\title{
Common atrium with single ventricle: a rare combination of two uncommon complex congenital heart diseases
}

Soumya Patra, Navin Agrawal, Usha MK, Jayaranganath M

Department of Cardiology, Sri Jayadeva Institute of Cardiovascular Sciences \& Research, Bengaluru, Karnataka, India

\section{Correspondence to}

Dr Navin Agrawal,

drnavinagrawal@gmail.com;

dr_navinagrawal@yahoo.co.in
CrossMark

To cite: Patra S, Agrawal N, MK U, et al. BMJ Case Rep Published online: [please include Day Month Year] doi:10.1136/bcr-2013200424

\section{DESCRIPTION}

Single ventricle (SV) defects, including common inflow of both the atria emptying into one ventricle, occur at an incidence of $0.05-0.1 / 10000$ live-births. ${ }^{1}$ Common atrium is a rare variety of interatrial communication which forms a type of endocardial cushion defect characterised by deficient atrial septum, the vestigial remnants

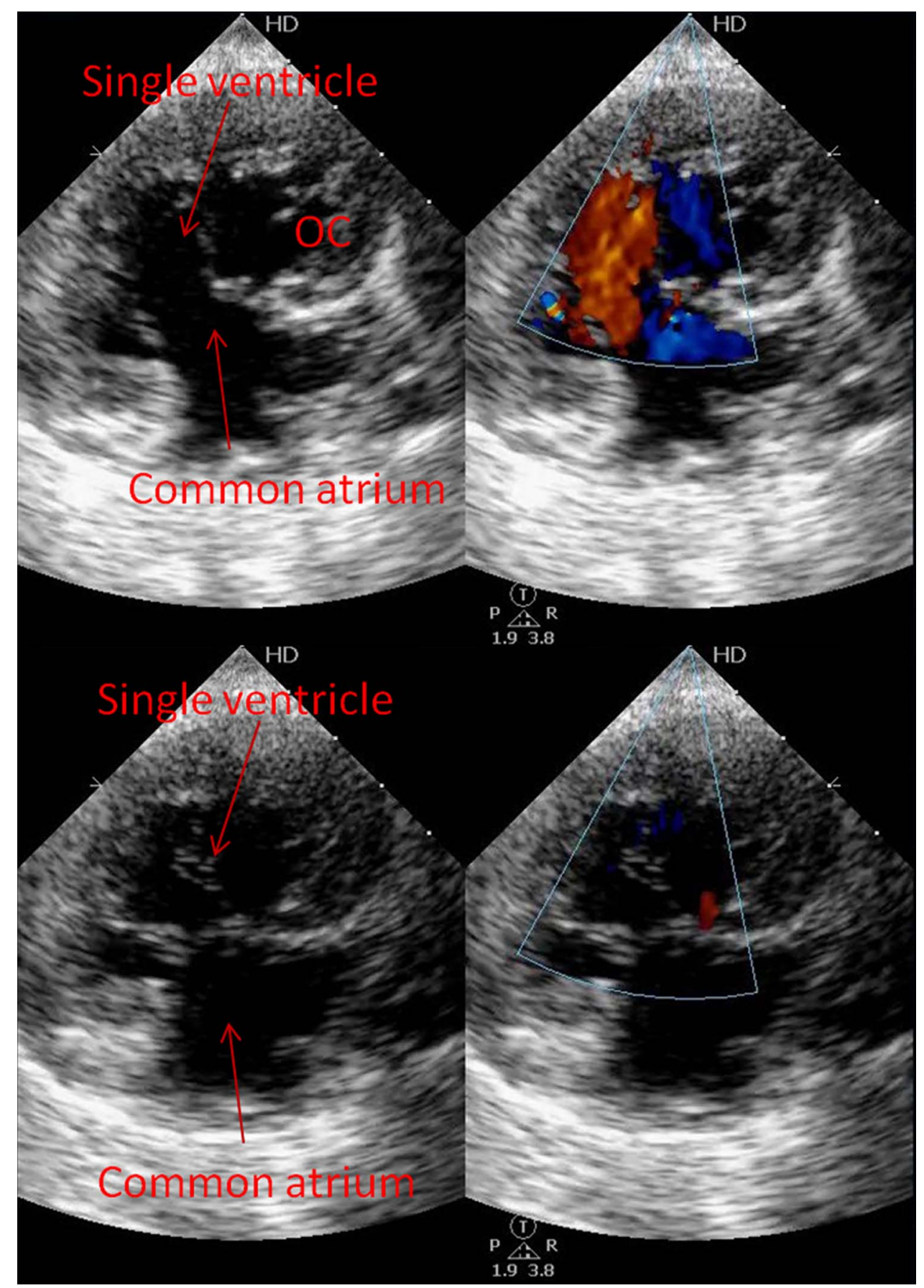

Figure 1 Apical 4-chamber view with colour compare image in diastole and systole shows common atrium, single ventricle and inverted outlet chamber. 


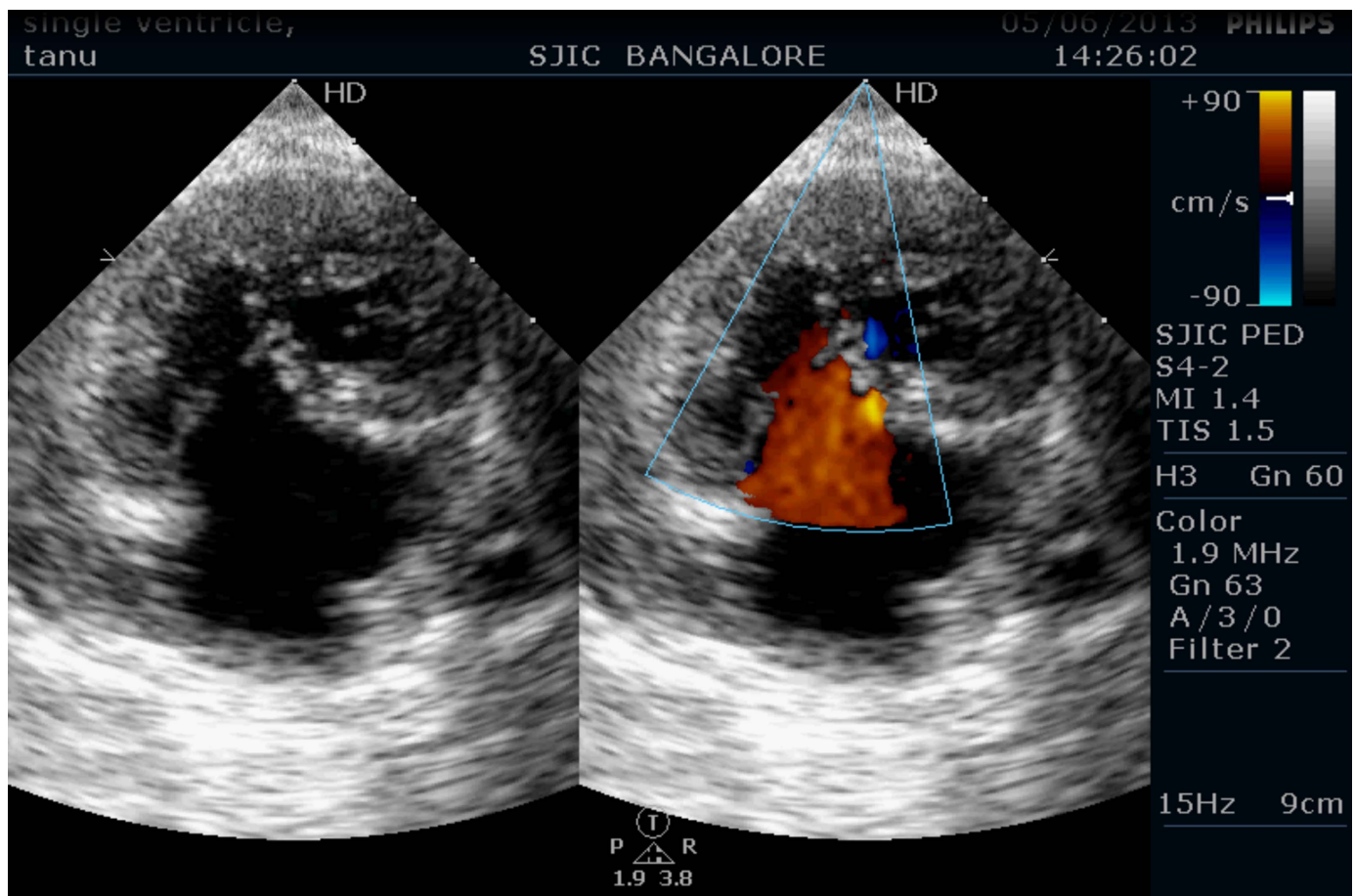

Video 1 Apical 4C view with colour compare shows common atrium, single ventricle and inverted outlet chamber.

sometimes remain as diaphanous strands of tissue. ${ }^{2}{ }^{3}$ Common atrium is very rarely seen in patients with $\mathrm{SV}^{3}$ In patients with common atrium and SV, there is mixing of arterial and venous blood in the common cardiac chamber which causes severe cyanosis and hypoxia in these patients. ${ }^{3} 4$
We report the case of a 6-month-old female baby who presented with central cyanosis, dyspnoea along with difficulty in feeding, fatigue and irritability since the neonatal period. She was the result of a full-term, caesarean delivery with an uneventful antenatal and perinatal course with no other obvious

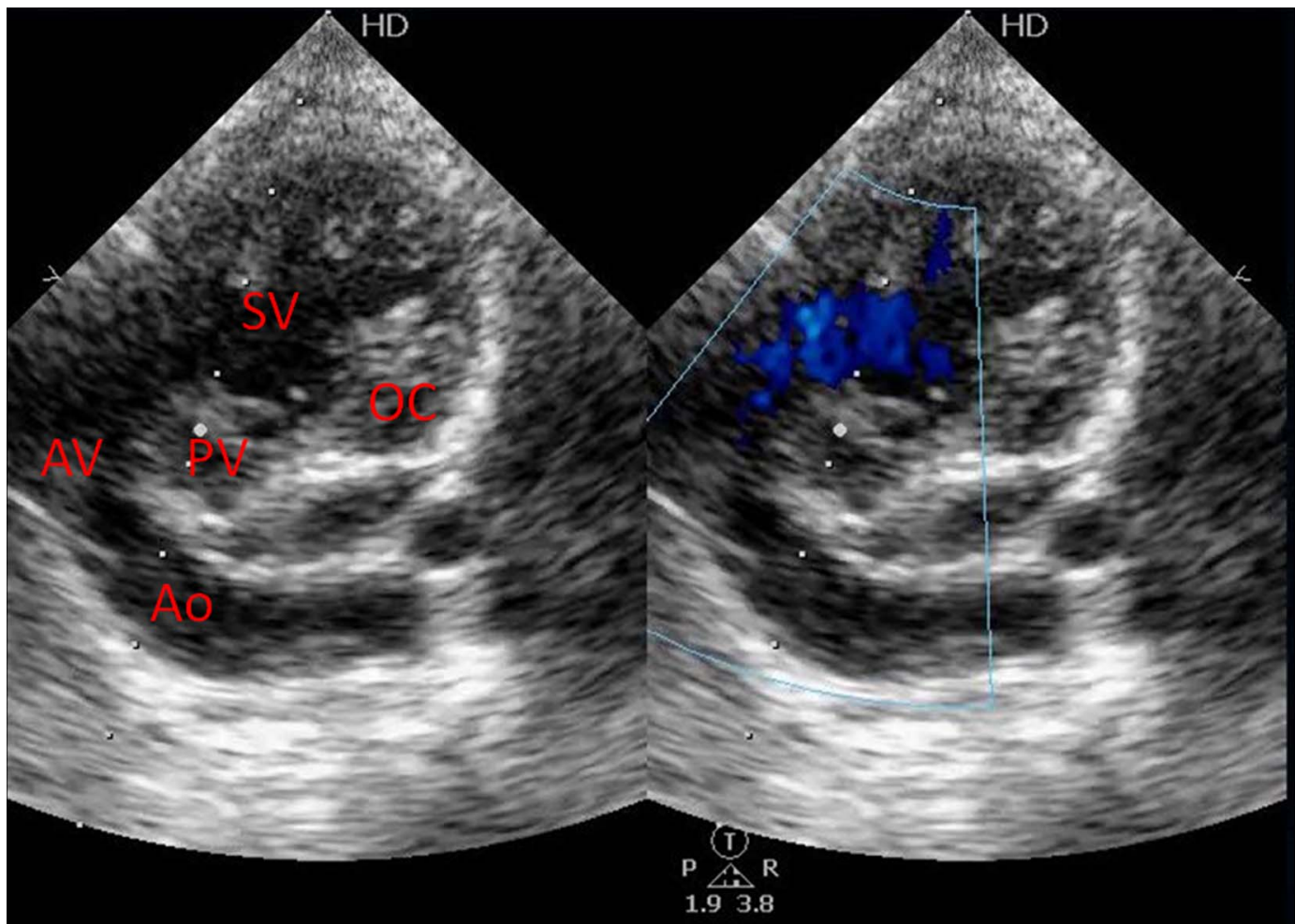

Figure 2 Modified 4-chamber view shows aorta arising from morphological left ventricle and hypoplastic pulmonary artery arising from outlet chamber. 


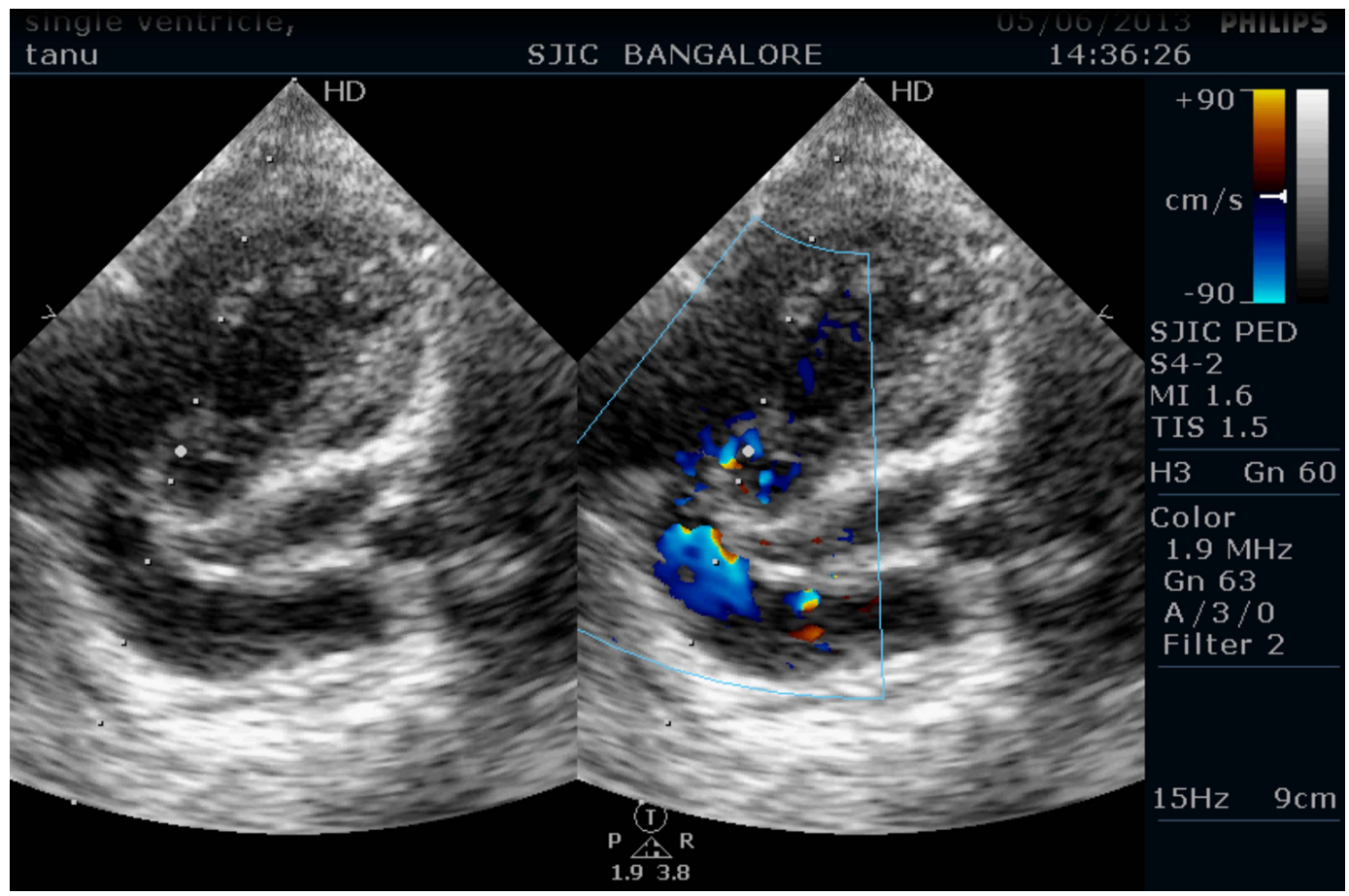

Video 2 Modified 4C view shows aorta (Ao) arising from morphological left ventricle and hypoplastic pulmonary artery arising from outlet chamber.

external malformations. She was the first-born child and her parents had no history of prior conception. The baby had a body weight of $6 \mathrm{~kg}$ and an oxygen saturation of $73 \%$ at room air. The auscultatory findings included a single first and second heart sound and soft grade II/VI ejection systolic murmur on physical examination. An initial working diagnosis of a complex cyanotic congenital heart disease with an admixture physiology was considered.

Echocardiogram revealed a common atrium and SV of left ventricular morphology with inverted outlet chamber (OC)

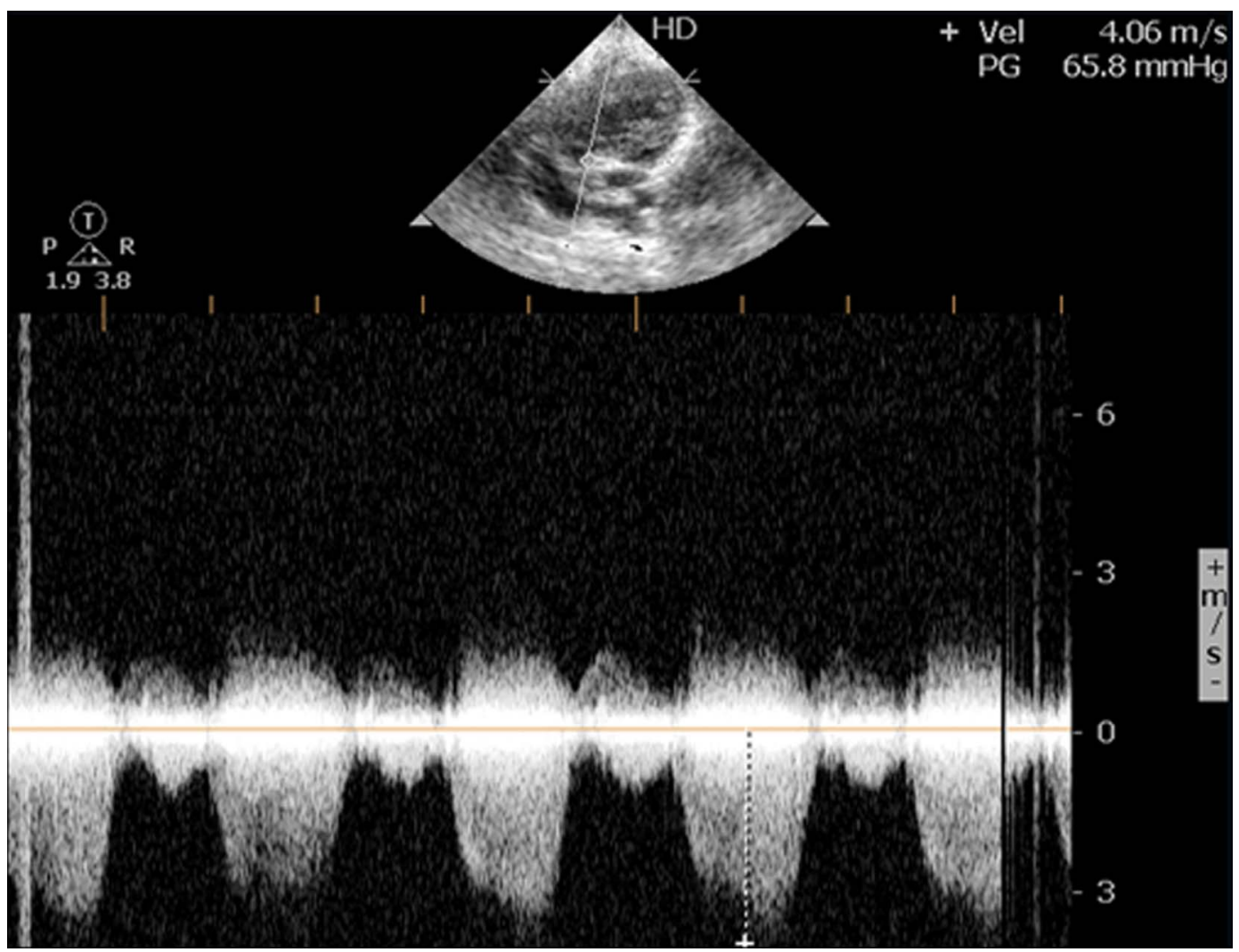

Figure 3 Continuous wave Doppler at pulmonary valve shows infundibular stenosis with gradient of $65 \mathrm{~mm} \mathrm{Hg}$. 


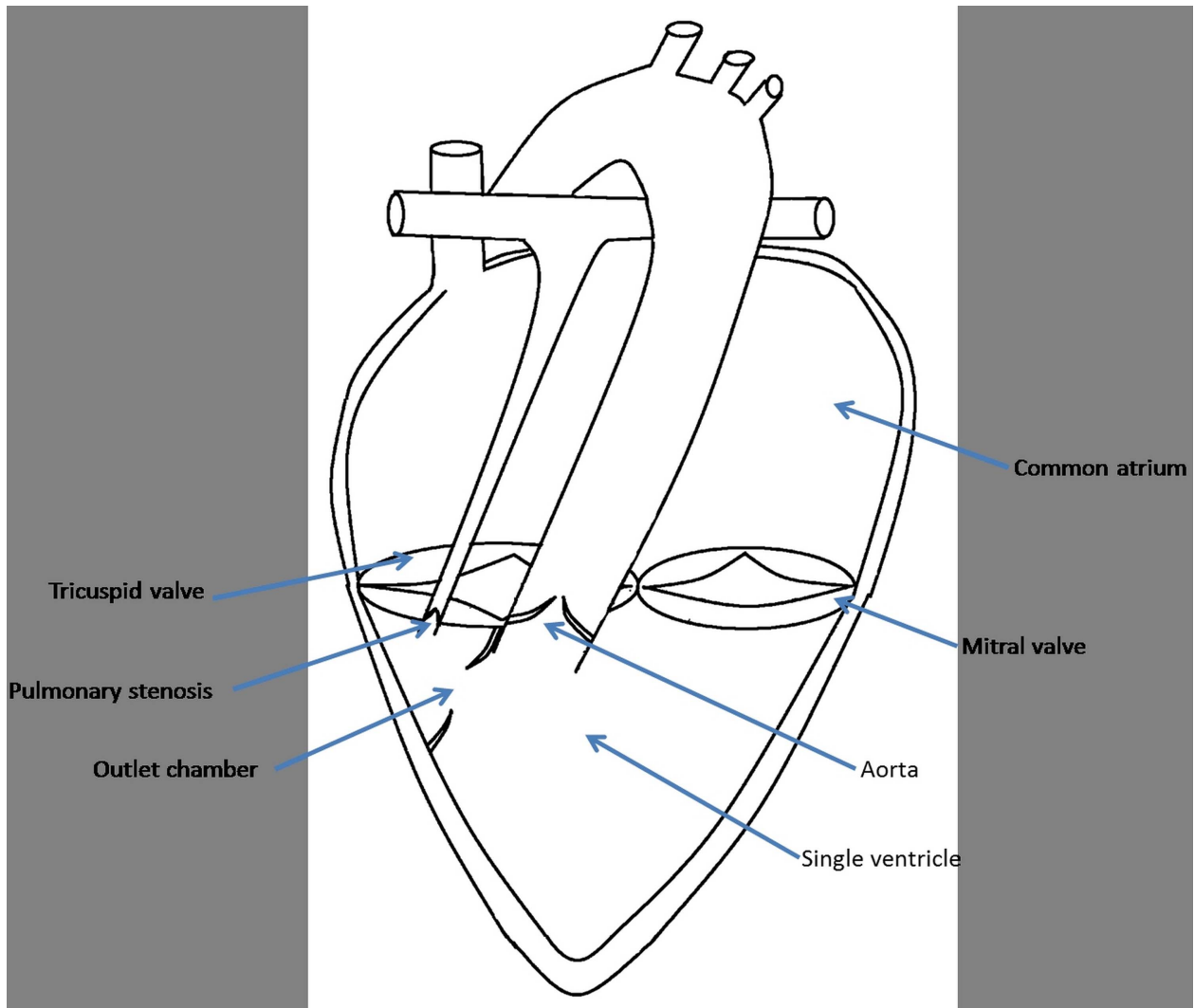

Figure 4 Illustrated line diagram of the patient's heart indicating the common atrium and single ventricle.

(figure 1; video 1). There was concordant relation of the major arteries with the aorta arising from morphological left ventricle (LV) and hypoplastic pulmonary artery arising from OC (figure 2; video 2). The patient had an infundibular stenosis with gradient of $65 \mathrm{~mm} \mathrm{Hg}$ (figures 3 and 4).

The patient underwent a palliative Blalock-Taussig shunt (BT shunt) surgery and was stable at 3 months of follow-up and was planned for a palliative Glenn shunt at the age of around 1012 months and subsequently a Fontan surgery at an age of around 3-4 years. Presently, the infant is maintaining saturation of around $85 \%$ and the gain of weight is appropriate for her age and has minimal symptoms, which are acceptable for a complex cyanotic congenital heart disease having undergone a palliative repair.

This case mimics a single-chambered heart in a human being. The prognosis of SV with common atrium is poor with high mortality rate of up to $50 \%$ in infancy. The median survival of single ventricle of LV morphology is 14 years, while that of the right ventricle morphology is 4 years. Patients having decreased pulmonary blood flow situation usually need a modified Blalock-Taussig shunt while those with increased blood flow may require a pulmonary artery banding procedure. This is usually followed up by a bidirectional Glenn operation as the second-stage after 3-6 months and a subsequent Fontan procedure at 2-3 years. Cases having complicated ventricular and arterial morphology and obstructed bulboventricular foramen may require complex surgical therapy, which is usually individualised according to the requirement of the case. The Fontan surgery is usually considered the definitive treatment for such cases which provides significantly improved prognosis as compared with the natural history of the disease. The surgical mortality of each case depends on the complexity of the lesion and the type of surgery planned at each stage of presentation and may range from $5 \%$ to $10 \%$ at each stage.

\section{Learning points}

- Single ventricle defects are rare and can present in various morphological forms which include cases with increased or decreased blood flow, and the association of another rare entity in the form of common atrium makes this case exceptional.

- Prompt surgical correction with initial palliation along the Fontan pathway, as was performed for this case, can ultimately lead to relatively better long-term outcome and survival compared with the natural history of the disease.

- High index of suspicion and echocardiography early in infancy is the key to appropriate management and can be lifesaving in such cases with complex cyanotic congenital heart disease as in this case.

Competing interests None.

Patient consent Obtained.

Provenance and peer review Not commissioned; externally peer reviewed. 


\section{REFERENCES}

1 Nabati M, Bagheri B, Habibi V. Coincidence of total anomalous pulmonary venous drainage to the superior vena cava, common atrium, and single ventricle: a very rare condition. Echocardiography 2013;30:E98-101.

2 Rastelli GC, Rahimtoola SH, Ongley PA, et al. Common atrium: anatomy, hemodynamics, and surgery. J Thorac Cardiovasc Surg 1968;55:834-41.
3 Munoz-Armas S, Gorrin JR, Anselmi G, et al. Single atrium. Embryologic, anatomic, electrocardiographic and other diagnostic features. Am J Cardiol 1968:21:639-52.

4 Kinare SG, Sivaraman A, Deshpande J. Single ventricle (morphologic study of 21 cases). Indian Heart J 1989:41:301-6.

Copyright 2013 BMJ Publishing Group. All rights reserved. For permission to reuse any of this content visit

http://group.bmj.com/group/rights-licensing/permissions.

BMJ Case Report Fellows may re-use this article for personal use and teaching without any further permission.

Become a Fellow of BMJ Case Reports today and you can:

- Submit as many cases as you like

- Enjoy fast sympathetic peer review and rapid publication of accepted articles

- Access all the published articles

- Re-use any of the published material for personal use and teaching without further permission

For information on Institutional Fellowships contact consortiasales@bmjgroup.com

Visit casereports.bmj.com for more articles like this and to become a Fellow 